\title{
Social distancing and influenza mortality in 1918 did not increase suicide rates in the United States
}

\author{
Hampton Gray Gaddy \\ Nuffield College, University of Oxford, UK
}

\section{A R T I C L E I N F O}

\section{Keywords:}

1918 influenza pandemic

United States

Suicide

Social distancing

Mental health

Social epidemiology

\begin{abstract}
A B S T R A C T
Recent research has suggested that the social distancing mandates introduced in the United States during the main waves of the 1918-20 influenza pandemic caused an increase in suicide rates. However, that finding relies on poor-quality, temporally mismatched data and has signs of omitted variable bias. Similarly, a long-standing finding that American suicide rates in 1918-20 were also boosted by the influenza mortality of the time has gone unquestioned in the literature, despite the original research admitting its risk of ecological fallacy. Using higherpowered mortality data, I cast doubt on both findings by analyzing the experiences of the pandemic in 43 of the largest American cities of the time. In line with some populations' experiences of COVID-19, I report tentative evidence that social distancing mandates during the 1918-20 pandemic may have been associated with decreased suicide rates. Larger, cross-national investigations of the effects of historical pandemics and social distancing mandates on mental health and suicide are needed.
\end{abstract}

\section{Introduction}

As during previous major outbreaks of infectious disease (Markel et al., 2007; Tognotti 2013), the need to save lives from the ongoing COVID-19 pandemic has led to the intermittent introduction of social distancing and quarantine requirements in most global populations. These restrictions tend to contribute to loneliness and decreased social integration, so they have prompted concerns since the beginning of the pandemic that they would contribute to suicide (e.g. Gunnell et al., 2020). Worsening mental health has been observed throughout the pandemic, likely due to the combined effects of the pandemic's death toll, the implemented social restrictions, and the socioeconomic consequences of both. However, the bulk of the available evidence suggests that the pandemic and its total effects have not been associated with an increase in suicide rates (Aknin et al., 2021; Meyerowitz-Katz et al., 2021; Pirkis et al., 2021).

Stack and Rockett (2021) challenge this literature somewhat by concluding that the social distancing requirements introduced in the United States in late 1918 and early 1919 in the face of the influenza pandemic of the time were associated with an increase in suicide rates. They correlate the number of days for which restrictions were introduced in 1918-19 with the 1918 rate of deaths attributed to suicide in 43 large cities. Controlling for the 1918 rate of deaths attributed to influenza, they found that a ten-day increase in the length of social distancing mandates was associated with an additional 0.43 annual suicides per 100,000 population (two-tailed $\mathrm{p}=0.032$; $95 \%$ CI: 0.05 , 0.81). In the authors' sample, the mean rate of deaths attributed to suicide in the baseline year of 1917 was 17.0 per 100,000 population and the mean length of social distancing in 1918 was 65.8 days. Therefore, the authors' finding equates to suggesting that the social distancing mandates in late 1918 increased the 1918 suicide rate in large American cities by an average of $16.6 \%$ relative to 1917 (95\% CI: $1.9 \%$, $31.4 \%)$.

In this article, I replicate the work of Stack and Rockett (2021) and test whether their findings are robust to the use of higher-quality data and controlling for baseline suicide rates. I also take the chance to re-evaluate Wasserman's (1992) suggestion that the pandemic's mortality itself was associated with higher suicide rates in the United States.

I note that the analysis used by Stack and Rockett (2021), in particular, can be improved in three important ways. First, their measure of mortality due to the pandemic itself can be improved. The authors utilize the annual rates of deaths attributed to influenza in 1918 (Bureau of the Census, 1923) as a control variable, but this is a poor measure of the mortality attributable to the pandemic. Excess mortality calculations are the gold-standard method for estimating pandemic death tolls (Beaney et al., 2020), estimates of the 1918-20 influenza pandemic's mortality based on annual rates are known to face a significant risk of bias (Andreasen \& Simonsen, 2011; Chandra \&

E-mail address: hampton.gaddy@nuffield.ox.ac.uk. 
Christensen, 2019), and a large proportion of the 1918-20 pandemic deaths in the United States were attributed to pneumonia, not influenza (Crosby, 1989). In light of these facts, it is not surprising that I find that the authors' pandemic mortality data is only moderately associated with the excess influenza and pneumonia mortality estimates published by Markel et al. (2007) for the 43 cities in the authors' sample $\left(R^{2}=0.42\right)$.

Second, Stack and Rockett's (2021) suicide and pandemic mortality data can be made more temporally specific. The authors utilize annual rates of deaths attributed to suicide and influenza that cover January 1 , 1918 to December 31, 1918 (Bureau of the Census, 1923), but they correlate them with social distancing mandate durations that spanned from September 18, 1918 to March 23, 1919 (Markel et al., 2007). This temporal mismatch is not monumentally worrying because most cities in the sample ceased mandating social distancing by the end of 1918; 75\% of the total days of mandates in the sample occurred before January 1 , 1919. However, the mismatch is still concerning because, using the attributed cause-of-death data from the Bureau of the Census, I find that the annual suicide rates in 1918 for the 43 cities in the sample have an imperfect correlation with the suicide rates from September 1918 to March $1919\left(\mathrm{R}^{2}=0.82\right)$.

Third, the robustness of Stack and Rockett's (2021) findings can be greatly improved by controlling for baseline suicide rates. In fact, doing so seems warranted based on one observation made by the authors themselves. The authors demonstrate that the duration of social distancing mandates in late 1918 and early 1919 was associated with suicide rates in 1918, but they also mention that suicide rates in 1917 and 1918 were highly correlated with each other. This suggests that suicide rates in 1917 were also associated with the length of social distancing mandates in 1918-19. In turn, this indicates that confounding alone may drive the authors' reported association between 1918 suicide rates and the length of social distancing.

Indeed, Fig. 1 suggests that education or a related aspect of human development is a key confounder within Stack and Rockett's (2021) work. Excluding the outlier of San Francisco, Fig. 1a displays the association between the duration of 1918-19 social distancing mandates and the 1918 suicide rate $(\mathrm{p}<0.001$; standardized coefficient: +0.526$)$ and Fig. $1 \mathrm{~b}$ displays the association between the literacy rate among people aged 10 and older at the 1920 census (Bureau of the Census, 1922) and the 1918 suicide rate $(\mathrm{p}<0.001$; standardized coefficient: +0.611$)$. The similarity of the direction and strength of the associations displayed suggests that education — for which literacy is a proxy—or some closely correlated aspect of human development is a confounding variable that explains the relationship that Stack and Rockett (2021) observe. In the period of pandemic, American cities with higher levels of education could have simply both had higher suicide rates and been prone to enact longer social distancing mandates. Therefore, I also test whether controlling for baseline suicide rates-which should capture most effects of education and other omitted variables-changes the observed association between social distancing mandates and suicide.

I find that Stack and Rockett's (2021) model of suicide rates is reproducible but that it is rendered statistically insignificant either by using higher-quality suicide and pandemic mortality estimates or by controlling for the available estimates of the baseline suicide rates of the period. Also, in all high-quality model specifications I find no evidence for pandemic mortality increasing suicides (cf. Wasserman, 1992), and in one model specification I find evidence for 1918-19 social distancing mandates actually being associated with reduced suicide rates.

\section{Methods}

I attempt to reproduce the model of American suicide rates in 1918 published by Stack and Rockett (2021) by following the methodology they describe in their article. I perform ordinary least-squares regression using the data on the duration of social distancing requirements in American cities published by Markel et al. (2007) and the annual 1918 rates of deaths attributed to suicide and influenza, respectively, published by the Bureau of the Census (1923). It has been suggested that the social distancing duration data published by Markel et al. (2007) was flawed in the cases of New York and Chicago (Barry, 2007), but I note that these concerns seem to be overblown (see Aimone, 2010).

However, I do test the effect of removing one outlier from the authors' sample. In 1918, San Francisco had a rate of deaths attributed to suicide that was $67 \%$ higher than the city with the next highest rate, and it saw similarly high suicide rates in the surrounding years. Additionally, the city had a relatively short period of social distancing requirements (50th percentile) given its influenza mortality in 1918 (86th percentile).
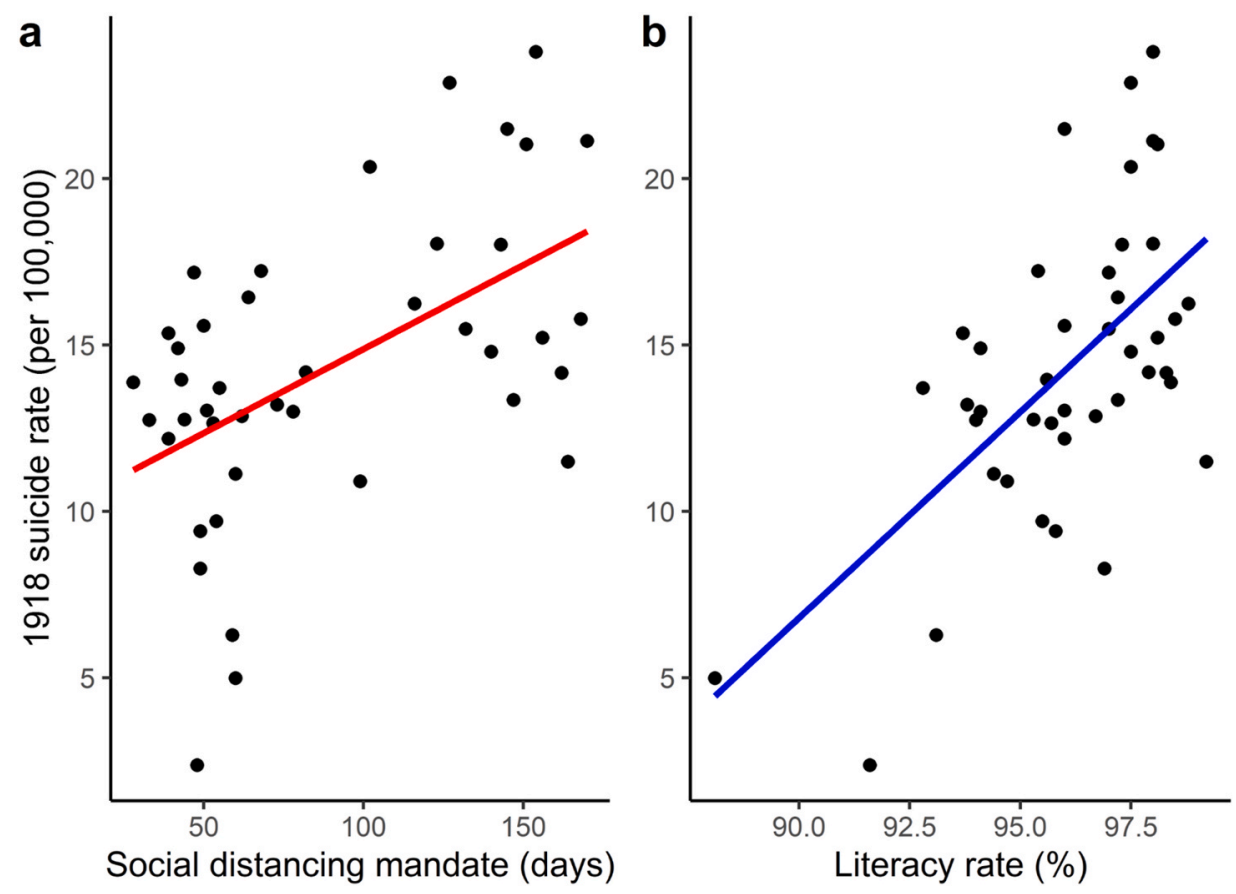

Fig. 1. The correlations of 1918-19 social distancing mandate duration and literacy with suicide rates in major American cities. 
As such, testing its removal both seems appropriate and makes it more likely that Stack and Rockett's (2021) hypothesis will be validated.

For the reasons described in the introduction, I also re-run Stack and Rockett's (2021) analysis using higher-quality data than originally used and re-run it using 1917 baseline suicide rates as a control variable. I source higher-quality pandemic mortality data from the local excess pneumonia and influenza mortality estimates produced by Markel et al. (2007) for the period of September 8, 1918 to February 22, 1919. I calculate higher-quality suicide rates for the period of social distancing mandates by dividing the total number of deaths attributed to suicide in the cities in the sample between the months of September 1918 and March 1919 (Bureau of the Census, 1920, 1921) by an exponential interpolation of the respective annual populations in each city based on the 1910 and 1920 census data reported by Gibson (1998). I calculate baseline suicide rates in the same manner, using annual suicide counts from 1917 (Bureau of the Census, 1919). Using an interpolated denominator may mean that suicide rates are slightly underestimated for the period of World War I solider mobilization, but the extent of proportional underestimation should not vary greatly between the cities in the sample, meaning that the underestimation does not have a significantly biasing effect on my regression results.

My quantitative analysis can be replicated in full using the provided $\mathrm{R}$ and data files. The data from the Bureau of the Census and Gibson (1998) is in the public domain and the data from Markel et al. (2007) is used and distributed in a limited way as fair use.

In my results, I report standardized regression coefficients to enable comparisons of the relative effect sizes of explanatory variables. This means that the regression coefficients are scaled to reflect how many standard deviations of change in the dependent variable is associated with a one standard deviation change in the independent variable. Additionally, I report adjusted $\mathrm{R}^{2}$ values and two-tailed tests of statistical significance, except where stated otherwise. Stack and Rockett (2021) report unadjusted $\mathrm{R}^{2}$ values and one-tailed tests without justifying those choices that otherwise inflate the apparent significance of their results. I consider it inappropriate to use a one-tailed test when examining the authors' hypothesis because it is plausible that social distancing in 1918 could have curbed suicide rates to some extent, as I discuss below.

\section{Results}

Table 1, Column 1 displays my close reconstruction of the authors' model. Controlling for the rate of deaths attributed to influenza in 1918, I find that the duration of social distancing requirements during the canonical 'second' and 'third' waves of the 1918-20 pandemic is associated with higher rates of deaths attributed to suicide in 1918 ( $\mathrm{p}=$ 0.024). I report this result with a slightly larger standardized effect size and a slightly smaller p-value than the original authors do; this is likely

\section{Table 1}

Regression table of the effects of 1918-19 social distancing mandate duration on suicide rates, including San Francisco.

\begin{tabular}{cllll}
\hline & $(1)$ & $(2)$ & $(3)$ & $(4)$ \\
\hline Mandate & $0.356^{*}$ & $0.032(0.090)$ & 0.183 & $-0.228^{*}$ \\
duration & $(0.151)$ & & $(0.166)$ & $(0.102)$ \\
$\begin{array}{c}\text { Pandemic } \\
\text { mortality }\end{array}$ & 0.179 & $0.150(0.084)$ & 0.029 & -0.099 \\
1917 suicide rate & $(0.151)$ & & $(0.166)$ & $(0.093)$ \\
& & $0.844^{* * *}$ & & $0.909^{* * *}$ \\
Observations & 43 & $(0.088)$ & & $(0.095)$ \\
Adjusted $\mathbf{R}^{2}$ & 0.086 & 43 & 43 & 43 \\
$\begin{array}{c}\text { Better-quality } \\
\text { data }\end{array}$ & No & 0.721 & -0.018 & 0.686 \\
& & No & Yes & Yes
\end{tabular}

Note: Regression coefficients are standardized, standardized standard errors are provided in parentheses, and two-tailed p-values are indicated as follows: $\mathrm{p}<$ $\left.\left.0.05{ }^{*}\right), \mathrm{p}<0.01{ }^{* *}\right), \mathrm{p}<0.001(* * *)$. due to slight discrepancies in data transcription.

This finding, i.e. that of Stack and Rockett (2021), is not robust to controlling for baseline suicide rates nor using higher-quality data. Table 1, Column 2 shows that the duration of social distancing mandates is not associated with 1918 suicide rates if one controls for 1917 suicide rates $(\mathrm{p}=0.725)$. Table 1 , Column 3 shows that the duration of social distancing mandates is not associated with 1918 suicide rates if one uses higher-quality suicide and pandemic mortality data than originally used by the authors $(p=0.277)$. Table 1 , Column 4 shows if one uses the available higher-quality data and controls for 1917 suicide rates, longer 1918-19 social distancing mandates in 43 large American cities were actually modestly associated with lower suicide rates over the period of September 1918 to March 1919 ( $\mathrm{p}=0.031$ ).

Table 2 re-runs the models presented in Table 1 after excluding the outlier of San Francisco, and it generally replicates the findings just described. Table 2, Column 2 shows that the duration of social distancing mandates is not associated with 1918 suicide rates if one controls for 1917 suicide rates $(\mathrm{p}=0.096$ ). This result can be reported as significant if one uses one-tailed tests, as the original authors do, but I maintain that doing so is not appropriate given the plausibility of an effect in the opposite direction and the tentative evidence for such an effect reported in Table 1, Column 4. Table 2, Column 4 does not replicate the negative association between social distancing and suicide reported in Table 1 , Column 4 ( $\mathrm{p}=0.118$ ). However, it does reaffirm my finding that Stack and Rockett's (2021) reported positive association between social distancing and suicide is rendered insignificant by using higher-quality data and controlling for baseline rates (one-tailed $\mathrm{p}=$ 0.941).

Also, I note that all models presented in Tables 1 and 2 report a null association between influenza (and pneumonia) mortality and suicide rates at the time of the pandemic.

\section{Discussion}

Tables 1 and 2 suggest that Stack and Rockett's (2021) reported positive association between social distancing and suicide is due to a combination of confounding and random error. Table 1 , Column 2 shows that controlling for baseline suicide rates makes the authors' finding insignificant; this suggests that Stack and Rockett's (2021) reported association is due to omitted variable bias. Table 1 , Column 3 shows that using higher-quality data makes the authors' finding insignificant; this suggests that the poor-quality data used contained enough random error that the authors' hypothesis was statistically significantly validated by chance. Table 2 shows that these findings are robust to the exclusion of the one outlier in the sample, San Francisco.

There is a theoretical reason that Stack and Rockett (2021) may have refrained from controlling for baseline suicide rates. As they discuss, the 1910s was a time of significantly improving quality and coverage of

Table 2

Regression table of the effects of 1918-19 social distancing mandate duration on suicide rates, excluding San Francisco.

\begin{tabular}{cllll}
\hline & $(1)$ & $(2)$ & $(3)$ & $(4)$ \\
\hline Mandate & $0.534^{* * *}$ & 0.192 & 0.235 & -0.202 \\
duration & $(0.140)$ & $(0.112)$ & $(0.163)$ & $(0.126)$ \\
$\begin{array}{c}\text { Pandemic } \\
\text { mortality }\end{array}$ & 0.105 & 0.146 & -0.110 & -0.151 \\
1917 suicide & $(0.140)$ & $(0.099)$ & $(0.163)$ & $(0.110)$ \\
rate & & $0.707^{* * *}$ & & $0.832^{* * *}$ \\
& & $(0.111)$ & & $(0.120)$ \\
Observations & 42 & & & \\
Adjusted $\mathrm{R}^{2}$ & 0.234 & 0.619 & 0.038 & 0.566 \\
$\begin{array}{c}\text { Better-quality } \\
\text { data }\end{array}$ & No & No & Yes & Yes \\
\end{tabular}

Note: Regression coefficients are standardized, standardized standard errors are provided in parentheses, and two-tailed p-values are indicated as follows: $\mathrm{p}<$ $0.05(*), \mathrm{p}<0.01(* *), \mathrm{p}<0.001(* * *)$. 
death registration in the United States. As such, they may have viewed the suicide rates in 1917 or earlier as insufficiently high-quality control variables. I would suggest that this is too theoretical of a concern compared to the imperative to execute proper time-series modeling techniques. Specifically, when using time-series data, the dependent variable's previous year value should be included as an independent control variable to control for autocorrelation and sharpen explanatory variable estimates.

However, in Appendix Table A1, I also show that controlling for literacy rates at the 1920 census, instead of 1917 baseline suicide rates, yields similar results to those in Tables 1 and 2. Unsurprisingly, the models presented have less explanatory power than those in Tables 1 and 2 that include baseline suicide rates, but they do reaffirm my conclusion that Stack and Rockett's (2021) finding is largely due to confounding. Moreover, they suggest that Stack and Rockett's (2021) conclusion may be due to confounding in the hypothetical manner that I proposed in the introduction: cities with more human development at the time of the pandemic may have simply been predisposed to both suffer higher suicide rates and impose longer lockdowns.

Otherwise, the analysis presented in this article makes a few other contributions to the literature on the 1918-20 influenza pandemic and suicide. Perhaps most importantly, it responds to a research call that seems to have gone largely unanswered for three decades. Previously, Wasserman (1992) found that crude national monthly death rates in the United States were positively associated with monthly suicide rates over the period of 1910-1920, inclusive, controlling for autocorrelation and variables including annual alcohol consumption estimates, monthly economic indicators, and the number of nationally publicized suicide stories per month. Given that crude national monthly death rates in that period were dominated by the 1918-20 influenza pandemic, Wasserman (1992) suggested that the mortality of the pandemic likely affected the American population such that suicide rates rose. However, the author also cautioned that his hypothesis would have to be re-examined using more disaggregated data, due to the potential for ecological bias affecting his analysis.

This article and that of Stack and Rockett (2021) seem to be the first published papers that have heeded Wasserman's (1992) research call, and they do not support his findings. The models in Tables 1 and 2 of this article and the model presented by Stack and Rockett (2021) in their Table 1 find no evidence that the local severity of the influenza pandemic was associated with increased suicide rates in 43 of the largest American cities of the time. This suggests that Wasserman's (1992) conclusion may have been due to confounding or other sources of bias.

Moreover, Stack and Rockett (2021) and I seem to present the first analyses of the 1918-20 influenza pandemic and contemporary suicide rates that make use of sub-national data from anywhere in the world. In doing so, we bolster a growing literature that has found little connection between the two on the national level. Bastiampillai, Allison, Brailey, et al. (2021) observe that suicide rates in the United States were notably lower during the period of the pandemic (1918-20) than in the surrounding years, and Bastiampillai, Allison, Smith, et al. (2021) make the same finding in New Zealand. In a more robust fashion, Rück et al. (2021) find that there was no relationship between suicide rates in Sweden and any of the three 20th-century influenza pandemics. Chang et al. (2020) contribute a high-quality analysis of the pandemic in Taiwan, but they only find evidence for 33 excess suicides (95\% CI: 3, 56) during a pandemic that caused an estimated 50,000 excess deaths in total in Taiwan (Hayami, 2009; Hsieh, 2009).

Finally, the full models presented in Tables 1 and 2 do suggest a new hypothesis within the field. Table 1, Column 4 suggests that American cities with longer social distancing mandates in late 1918 and early 1919 had lower suicide rates over that period, controlling for pandemic mortality in that period and 1917 baseline suicide rates. Table 2, Column 4 shows that the statistical significance of that finding depends on the inclusion of San Francisco, but even excluding San Francisco, the data suggest that a one standard deviation increase in the duration of social distancing requirements ( $\mathrm{SD}=46.9$ days) was associated with a mean 0.202 standard deviation decrease in suicide rates between September 1918 and March 1919, or a mean decline in the contemporary suicide rate of $9 \%(\mathrm{p}=0.118$; $95 \% \mathrm{CI}:-2 \%, 20 \%)$.

This is not a conclusive finding, but it does warrant more exploration. The imposition of social distancing mandates early in the COVID19 pandemic was temporally correlated with a moderate reduction in suicide rates in several global populations, including Chile, Ecuador, Japan, South Korea, and New Zealand (Pirkis et al., 2021). The current evidence does not yet indicate whether that decline in suicide was due to the general experience of the pandemic or partly due to an effect of lockdown itself. However, such a latter effect is plausible. Durkheimian hypotheses of how social changes impact social integration and therefore suicide risk can often be contradictory (see Wasserman, 1992). Social distancing mandates undoubtedly limited individuals' social interactions outside of the home, but they could have intensified some people's sense of the severity of pandemic and thereby increased their social solidarity in the face of the crisis. This was observed to have happened during the first global wave of the COVID-19 pandemic (see Collins, 2020; Morrow, 2020). Lockdowns could have also limited individuals' exposure to certain social stressors, and the introduction of longer and more severe social distancing mandates could have assuaged some individuals' fears of what consequences the pandemic would have for them and their significant others, thereby giving them more existential security.

If longer 1918-19 social distancing mandates were found to be robustly related to lower suicide rates, that would not be the first finding that associates lockdowns with societal benefits that are distinct from the reductions in pandemic mortality that they most directly foster. That finding would join the observation by Wagner et al. (2020) that American cities with longer 1918-19 mandates saw their post-pandemic fertility rates rise to pre-pandemic levels the fastest. It would also join the findings that some lockdowns early in the COVID-19 pandemic were associated with reduced air pollution attributable mortality (Chossière et al., 2021) and fewer violent deaths (see Calderon-Anyosa \& Kaufman, 2021).

\section{Conclusions}

Globally, there has been little work on the effects of the 1918-20 influenza pandemic on mental health. As discussed above, the previously reported associations between the pandemic and contemporary suicide rates have been weak or null. Otherwise, one limited study reported no effect of the pandemic on acute compulsory psychiatric admissions in Amsterdam (van der Heide \& Coutinho, 2006). Two recent systematic reviews on the experience of mental health during epidemics found no other literature relating to the 1918-20 influenza pandemic (Neelam et al., 2021; Rogers et al., 2021)—although the search strategies of the reviews may have been too narrow. Additionally, I am aware that two research teams have reported no connection between the pandemic and psychiatric admissions in Croatia (Milovan Delić and Plavšić, 2020; Vukojević et al., 2021) and that Dimka and Mamelund (2020) report on the high case-fatality of medically institutionalized individuals, including psychiatric patients, in Norway.

Other work suggests a longer-term link between the 1918-20 influenza pandemic and poor mental health. Some studies of later influenza epidemics have reported that in utero exposure to influenza is a risk factor for developing psychiatric conditions (Kępińska et al., 2020; Turner et al., 2021). Several studies of the 1918-20 influenza have also reported that in utero exposure to the pandemic was associated with various life outcomes that could have been a risk factor for poor mental health, e.g. higher rates of physical disability (Almond, 2006), higher rates of chronic disease and hospitalization (Acquah et al., 2017; Lin \& Liu, 2014), and lower levels of education (González et al., 2021; Lin \& Liu, 2014; Percoco, 2016). However, it is also established that estimates of the effects of in utero exposure to 1918-20 pandemic can be both 
highly inconsistent (Cohen et al., 2010; Vollmer \& Wójcik, 2017, p. 92) and systematically biased (Beach et al., 2018; Brown \& Thomas, 2018). Much more work must be done to produce a better understanding of the 1918-20 influenza pandemic's immediate and long-term impacts on mental health, or lack thereof. This article contributes a few small steps in that direction.

To my knowledge, this article and that of Stack and Rockett (2021) present the first studies that correlate local severity in mental health outcomes with the local severity of the pandemic, and in opposition to Wasserman (1992), both teams agree that large American cities that were more severely struck by the pandemic in 1918 did not see higher rates of deaths attributed to suicide in 1918. In this article, I contend that the duration of social distancing in those cities was also not positively associated with suicide rates, in opposition to Stack and Rockett (2021). In fact, I point to limited evidence that social distancing duration may have actually been negatively associated with suicide rates.

The effects of the 1918-20 influenza pandemic and the ongoing COVID-19 pandemic on mental health are an active area of research, and one that will hopefully become more active. I only caution that researchers who seek to understand historical pandemics, especially for the sake of understanding modern pandemics, should learn from some of the previous mistakes of the literature. Like the COVID-19 pandemic, the 1918-20 influenza pandemic was complex, heterogeneous, and sometimes counterintuitive. Attempts to reduce it to uncomplicated models often do not reproduce (see e.g. Andreasen \& Simonsen, 2011; Chandra \& Christensen, 2019; Nishimura \& Ohkusa, 2016).

\section{Funding}

The author is supported by the Economic and Social Research Council [grant number ES/P000649/1].

\section{Data availability}

All data and code related to this project is available at https://doi. org/10.17605/OSF.IO/2YU94.

\section{Declaration of competing interest}

None.

\section{Appendix A. Supplementary data}

Supplementary data to this article can be found online at https://doi. org/10.1016/j.ssmph.2021.100944.

\section{References}

Acquah, J. K., Dahal, R., \& Sloan, F. A. (2017). 1918 influenza pandemic: In utero exposure in the United States and long-term impact on hospitalizations. American Journal of Public Health, 107(9), 1477-1483. https://doi.org/10.2105/ A.JPH.2017.303887

Aimone, F. (2010). The 1918 influenza epidemic in New York city: A review of the public health response. Public Health Reports, 125(Suppl 3), 71-79. https://doi.org/ 10.1177/00333549101250S310

Aknin, L. B., De Neve, J. E., Dunn, E. W., Fancourt, D., Goldberg, E., Helliwell, J., Jones, S., Karam, E., Layard, R., Lyubomirsky, S., Rzepa, A., Saxena, S., Thornton, E., VanderWeele, T., Whillans, A., Zaki, J., Caman, O. K., \& Amor, Y. B. (2021). Mental health during the first year of the COVID-19 pandemic: A review and recommendations for moving forward. Perspectives on Psychological Science. https://doi.org/10.31234/ osf.io/zw93g

Almond, D. (2006). Is the 1918 influenza pandemic over? Long-term effects of in utero influenza exposure in the post-1940 U.S. Population. Journal of Political Economy, 114(4), 672-712. https://doi.org/10.1086/507154

Andreasen, V., \& Simonsen, L. (2011). The perils of using annual all-cause mortality data to estimate pandemic influenza burden. PubMed Vaccine, 29(2), B49-B55. https:// doi.org/10.1016/j.vaccine.2011.03.061.

Barry, J. M. (2007). Comments on the nonpharmaceutical interventions in New York City and Chicago during the 1918 flu pandemic. Journal of Translational Medicine, 5, 65. https://doi.org/10.1186/1479-5876-5-65
Bastiampillai, T., Allison, S., Brailey, J., Ma, M., Chan, S. K. W., \& Looi, J. C. L. (2021). Pandemics and social cohesion: 1918-1920 influenza pandemic and the reduction in US suicide rates. The Primary Care Companion For CNS Disorders, 23(3). https://doi. org/10.4088/PCC.20com02882

Bastiampillai, T., Allison, S., Smith, D., Mulder, R., \& Looi, J. C. (2021). The Spanish Flu pandemic and stable New Zealand suicide rates: Historical lessons for COVID-19. New Zealand Medical Journal, 134(1541), 134-137. https://journal.nzma.org.nz/jour nal-articles/the-spanish-flu-pandemic-and-stable-new-zealand-suicide-rates-historic al-lessons-for-covid-19.

Beach, B., Ferrie, J. P., \& Saavedra, M. H. (2018). Fetal shock or selection? The 1918 influenza pandemic and human capital development. Working Paper No. 24725). National Bureau of Economic Research. https://doi.org/10.3386/w24725.

Beaney, T., Clarke, J. M., Jain, V., Golestaneh, A. K., Lyons, G., Salman, D., \& Majeed, A. (2020). Excess mortality: The gold standard in measuring the impact of COVID-19 worldwide? Journal of the Royal Society of Medicine, 113(9), 329-334. https://doi. org/10.1177/0141076820956802

Brown, R., \& Thomas, D. (2018). On the long term effects of the 1918 U.S. Influenza pandemic. https://www.ibread.org/wp-content/uploads/2021/03/wp_569.pdf.

Bureau of the Census. (1919). Mortality statistics, 1917. Government Printing Office. https ://www.cdc.gov/nchs/data/vsushistorical/mortstatsh_1917.pdf.

Bureau of the Census. (1920). Mortality statistics, 1918. Government Printing Office. https ://www.cdc.gov/nchs/data/vsushistorical/mortstatsh_1918.pdf.

Bureau of the Census. (1921). Mortality statistics, 1919. Government Printing Office. https ://www.cdc.gov/nchs/data/vsushistorical/mortstatsh_1919.pdf.

Bureau of the Census. (1922). Fourteenth census of the United States, taken in the year 1920, 2. Government Printing Office. https://www.census.gov/library/publications/19 22/dec/vol-02-population.html.

Bureau of the Census. (1923). Mortality rates, 1910-1920. Government Printing Office. https://www.cdc.gov/nchs/data/vsushistorical/mortrates_1910-1920.pdf.

Calderon-Anyosa, R. J. C., \& Kaufman, J. S. (2021). Impact of COVID-19 lockdown policy on homicide, suicide, and motor vehicle deaths in Peru. Preventive Medicine, 143, 106331. https://doi.org/10.1016/j.ypmed.2020.106331

Chandra, S., \& Christensen, J. (2019). Re: "Reassessing the global mortality burden of the 1918 influenza pandemic. American Journal of Epidemiology, 188(7), 1404-1406. https://doi.org/10.1093/aje/kwz044

Chang, Y.-H., Chang, S.-S., Hsu, C.-Y., \& Gunnell, D. (2020). Impact of pandemic on suicide: Excess suicides in taiwan during the 1918-1920 influenza pandemic. Journal of Clinical Psychiatry, 81(6). https://doi.org/10.4088/JCP.20113454

Chossière, G. P., Xu, H., Dixit, Y., Isaacs, S., Eastham, S. D., Allroggen, F., Speth, R. L., \& Barrett, S. R. H. (2021). Air pollution impacts of COVID-19-related containment measures. Science Advances, 7(21), eabe1178. https://doi.org/10.1126/sciadv. abe1178

Cohen, A., Tillinghast, J., \& Canudas-Romo, V. (2010). No consistent effects of prenatal or neonatal exposure to Spanish flu on late-life mortality in 24 developed countries. Demographic Research, 22, 579-634. https://doi.org/10.4054/DemRes.2010.22.20

Collins, R. (2020). Social distancing as a critical test of the micro-sociology of solidarity. American Journal of Cultural Sociology, 8(3), 477-497. https://doi.org/10.1057/ s41290-020-00120-Z

Crosby, A. W. (1989). America's forgotten pandemic: The influenza of 1918. Cambridge University Press.

Dimka, J., \& Mamelund, S.-E. (2020). 1918 influenza outcomes among institutionalized Norwegian populations: Implications for disability-inclusive pandemic preparedness. Scandinavian Journal of Disability Research, 22(1), 175-186. https://doi.org/ $10.16993 /$ sjdr.725

Gibson, C. (1998). Population of the 100 largest cities and other urban places in the United States: 1790 to 1990 (Working Paper POP-WP027). United States Bureau of the Census https://www.census.gov/library/working-papers/1998/demo/POP-twps 0027.html.

González, F. A. I., Dip, J. A., \& London, S. (2021). Long-lasting effects of pandemics: The case of the 1918 influenza pandemic in Argentina. Spatial and Spatio-Temporal Epidemiology, 37, 100409. https://doi.org/10.1016/j.sste.2021.100409

Gunnell, D., Appleby, L., Arensman, E., Hawton, K., John, A., Kapur, N., Khan, M., O'Connor, R. C., Pirkis, J., Appleby, L., Arensman, E., Caine, E. D., Chan, L. F., Chang, S.-S., Chen, Y.-Y., Christensen, H., Dandona, R., Eddleston, M., Erlangsen, A., \& Yip, P. S. (2020). Suicide risk and prevention during the COVID-19 pandemic. The Lancet Psychiatry, 7(6), 468-471. https://doi.org/10.1016/S2215-0366(20)30171-1

Hayami, A. (2009). An estimation of Spanish influenza mortality in imperial Japan: 1918-20. In S. Kurosu, T. Bengtsson, \& C. Campbell (Eds.), Demographic responses to economic and environmental crises (pp. 282-300). http://web.archive.org/web/20200 718105703/https://www.iussp.org/sites/default/files/AllArticles.pdf.

van der Heide, D. H., \& Coutinho, R. A. (2006). No effect of the 1918 influenza pandemic on the incidence of acute compulsory psychiatric admissions in Amsterdam. European Journal of Epidemiology, 21(3), 249-250. https://doi.org/10.1007/s10654006-0007-9

Hsieh, Y.-H. (2009). Excess deaths and immunoprotection during 1918-1920 influenza pandemic, taiwan. Emerging Infectious Diseases, 15(10), 1617-1619. https://doi.org/ 10.3201/eid1510.080811. PubMed.

Kępińska, A. P., Iyegbe, C. O., Vernon, A. C., Yolken, R., Murray, R. M., \& Pollak, T. A. (2020). Schizophrenia and influenza at the centenary of the 1918-1919 Spanish influenza pandemic: Mechanisms of psychosis risk. Frontiers in Psychiatry, 11, 72. https://doi.org/10.3389/fpsyt.2020.00072

Lin, M.-J., \& Liu, E. M. (2014). Does in utero exposure to illness matter? The 1918 influenza epidemic in taiwan as a natural experiment. Journal of Health Economics, 37, 152-163. https://doi.org/10.1016/j.jhealeco.2014.05.004

Markel, H., Lipman, H. B., Navarro, J. A., Sloan, A., Michalsen, J. R., Stern, A. M., \& Cetron, M. S. (2007). Nonpharmaceutical interventions implemented by US cities 
during the 1918-1919 influenza pandemic. Journal of the American Medical Association, 298(6), 644. https://doi.org/10.1001/jama.298.6.644

Meyerowitz-Katz, G., Bhatt, S., Ratmann, O., Brauner, J. M., Flaxman, S., Mishra, S., Sharma, M., Mindermann, S., Bradley, V., Vollmer, M., Merone, L., \& Yamey, G. (2021). Is the cure really worse than the disease? The health impacts of lockdowns during COVID-19. BMJ Global Health, 6(8), Article e006653. https://doi.org/ 10.1136/bmjgh-2021-006653

Milovan Delić, I., \& Plavšić, M. (2020). Spanish flu and mental disorders in the Margraviate of Istria at the end of WWI. Acta Histriae, 28(1), 59-74. https://doi.org/ 10.19233/AH.2020.04

Morrow, J. (2020). Alone together: Finding solidarity in a time of social distance. Space and Culture, 23(3), 315-319. https://doi.org/10.1177/1206331220938643

Neelam, K., Duddu, V., Anyim, N., Neelam, J., \& Lewis, S. (2021). Pandemics and preexisting mental illness: A systematic review and meta-analysis. Brain, Behavior, \& Immunity - Health, 10, 100177. https://doi.org/10.1016/j.bbih.2020.100177

Nishimura, H., \& Ohkusa, Y. (2016). Verification of the overestimation of the "deaths associated with influenza pandemic of 1918-1919, Japan" claimed in a demographic study. Japanese Journal of Infectious Diseases, 69(1), 12-17. https://doi.org/10.7883/ yoken.JJID.2014.362. PubMed.

Percoco, M. (2016). Health shocks and human capital accumulation: The case of Spanish flu in Italian regions. Regional Studies, 50(9), 1496-1508. https://doi.org/10.1080/ 00343404.2015.1039975

Pirkis, J., John, A., Shin, S., DelPozo-Banos, M., Arya, V., Analuisa-Aguilar, P., Appleby, L., Arensman, E., Bantjes, J., Baran, A., Bertolote, J. M., Borges, G., Brečić, P., Caine, E., Castelpietra, G., Chang, S.-S., Colchester, D., Crompton, D., Curkovic, M., \& Spittal, M. J. (2021). Suicide trends in the early months of the COVID-19 pandemic: An interrupted time-series analysis of preliminary data from 21 countries. The Lancet Psychiatry, 8(7), 579-588. https://doi.org/10.1016/S22150366(21)00091-2

Rogers, J. P., Chesney, E., Oliver, D., Begum, N., Saini, A., Wang, S., McGuire, P., FusarPoli, P., Lewis, G., \& David, A. S. (2021). Suicide, self-harm and thoughts of suicide or self-harm in infectious disease epidemics: A systematic review and meta-analysis. Epidemiology and Psychiatric Sciences, 30, e32. https://doi.org/10.1017/ S2045796021000214

Rück, C., Mataix-Cols, D., Malki, K., Adler, M., Flygare, O., Runeson, B., \& Sidorchuk, A. (2021). Swedish nationwide time series analysis of influenza and suicide deaths from 1910 to 1978. BMJ Open, 11(7), Article e049302. https://doi.org/10.1136/bmjopen2021-049302

Stack, S., \& Rockett, I. R. H. (2021). Social distancing predicts suicide rates: Analysis of the 1918 flu pandemic in 43 large cities, research note. Suicide and Life-Threatening Behavior. https://doi.org/10.1111/sltb.12729. sltb.12729.

Tognotti, E. (2013). Lessons from the history of quarantine, from plague to influenza A. Emerging Infectious Diseases, 19(2), 254-259. https://doi.org/10.3201/ eid1902.120312

Turner, A. J., Fichera, E., \& Sutton, M. (2021). The effects in-utero exposure to influenza on mental health and mortality risk throughout the life-course. Economics and Human Biology, 43, 101059. https://doi.org/10.1016/j.ehb.2021.101059

Vollmer, S., \& Wójcik, J. (2017). The long-term consequences of the global 1918 influenza pandemic: A systematic analysis of 117 IPUMS international census data sets (CINCH working paper series No. 1708. University of Duisburg-Essen. https://ideas.repec. org/p/duh/wpaper/1708.html.

Vukojević, J., Đuran, N., Žaja, N., Sušac, J., Šekerija, M., \& Savić, A. (2021). 100 Years apart: Psychiatric admissions during Spanish flu and COVID-19 pandemic. Psychiatry Research, 303, 114071. https://doi.org/10.1016/j.psychres.2021.114071

Wagner, S., Tropf, F. C., Cavalli, N., \& Mills, M. C. (2020). Pandemics, public health interventions and fertility: Evidence from the 1918 influenza. SocArXiv. https://doi.org/ 10.31235/osf.io/f3hv8

Wasserman, I. M. (1992). The impact of epidemic, war, prohibition and media on suicide: United States, 1910-1920. Suicide and Life-Threatening Behavior, 22(2), 240-254. https://doi.org/10.1111/j.1943-278X.1992.tb00231.x 